\section{AÇIK ERIŞìM}

Editör:

Deniz BEDIR

Erzurum Teknik Üniversitesi, Spor Bilimleri

Fakültesi, Erzurum, Türkiye.

Hakemler:

Kübra ÖZDEMIR

Atatürk Üniversitesi, Spor Bilimleri Fakültesi,

Erzurum, Türkiye.

Nihal AKOĞUZ YAZICI

Recep Tayyip Erdoğan Üniversitesi, Spor Bilimleri Fakültesi, Rize, Türkiye.

Iletişim:

Emine ARIKAN

eminearikan@stu.aydin.edu.tr

Tarihler:

Geliş: 30.11.2021

Kabul: 17.12.2021

Yayınlanma: 31.12 .2021

Künye:

Arıkan E. (2021). Güncel psikoterapide doğu temelli geleneksel yaklaşımlar: Eskinin yeniden keşfi ve güncel olarak yorumlanmast. IntJourExerPsyc,

$3(2): 85-94$

https://doi.org/10.51538/intjourexerpsyc.1030 722

\section{Güncel Psikoterapide Doğu Temelli Geleneksel Yaklaşımlar: Eskinin Yeniden Keșfi ve Güncel Olarak Yorumlanması}

\author{
Eastern-Based Traditional Approaches in \\ Contemporary Psychotherapy: Rediscovery and \\ Current Interpretation of the Past
}

\section{Emine Arıkan \\ İstanbul Aydın Üniversitesi, Lisansüstü Ĕ̌itim Enstitüsü, İstanbul, Türkiye.}

ÖZ: Yapılan çalışmanın amacı, Doğu geleneksel meditatif yaklaşımlarının günümüz psikoloji dünyasını nasıl etkilediği ve güncel psikoterapilere nasıl uyarlanmaya çalışıldığının incelenmesidir. Ayrıca bu yaklaşımlara getirilen eleştirilerin alanyazın taraması ile incelenmesi çalışmanın bir diğer amacıdır. Bilimsel araştırma bulguları oldukça olumlu veriler sunmasına rağmen hem operasyonel tanımlar hem de standart eğitim modelleri geliştirilebilmesi için daha fazla görgül çalışmaya ihtiyaç duyulduğunu gösteren analizlerin yorumlarına yer verilmiştir.

Anahtar Kelimeler: psikoterapi, meditasyon, bilinçli farkındalık, qigong, zihinbeden terapileri.

ABSTRACT: In this review article, how Eastern traditional meditative approaches affect today's psychology world, how they are tried to be adapted to current psychotherapies, their effects on various psychopathologies, the results obtained, and finally the criticisms are examined by scanning the literature. The comments on the analysis that more empirical studies are needed to develop both operational definitions and Standard training models, although scientific research findings have provided quite positive data so far, are shared.

Keywords: psychotherapy, meditation, mindfulness, qigong, mind-body therapies. 


\section{GİRIŞ}

Bu makale çalışmasında, özellikle son on yıllardır psikoterapi alanında artarak uygulanan, köklerini kadim Doğu yaklaşımlarından alan farkındalık ve meditasyon temelli yaklaşımlar ele alınmıştır. Birinci ve ikinci kuşak bilişsel davranışçı psikoterapi yöntemlerinin izleğinde gelinen noktayla birlikte üçüncü kuşak olarak adlandırılan bu meditatif yaklaşımların günümüz insanının psikolojik ihtiyaçlarını karşılamak için nasıl uyarlandığı, dünyada özellikle Amerika ve kıta Avrupa'sında “duygu temelli psikoterapi” uygulamalarına nasıl eklemlendiği, çeşitli psikopatolojilere etkileri, alınan sonuçlar, getirilen eleştiriler ve bu uygulamaların Türkiye'de aldığ 1 yol, alan yazınından taramalarla incelenmiştir.

\subsection{Bilişsel Davranışçı Psikoterapilerde Üçüncü Kuşak}

Bilişsel davranışçı terapilerin kuramsal kökenlerinin 1925'lere kadar uzanmasına rağmen bunların uygulama alanına yansımalarının 1950'lerle birlikte hızlandığı görülmektedir. Alanyazınında uygulamaların çeşitlenmesi ile temel olarak üç kuşağın yer aldığı raporlanmaktadır (Hayes, 2004).

Birinci kuşak; davranışçı yaklaşımların baskın ve etkin olduğu uygulamalar olarak karşımıza çıkmaktadır. Davranışların gözlenmesine, yorumlanmasına ve değiştirilmesine odaklanılmıştır.

İkinci kuşak; bilişsel davranışçı yaklaşımların baskın ve etkin olduğu uygulamalardır. Bu kuşakta, nesnel davranışçılık yerini, uyarıcı ve tepki arasındaki ilişkide aracı olan bilişlerin önemine bırakmıştır. Birinci kuşağın sonuna doğru ikinci kuşağın yaratıcıları olan araştırmacılar; işlevselliğin bozulması ile ilişkili davranışların ortaya çıkmasında ve sürdürülmesinde işlevsel olmayan bilişlerin etkin olduğunu belirtmiş̧lerdir ve tedavi yaklaşımlarında işlevsel olmayan düşünce ve davranışların değiştirilmesine yoğunlaşmışlardır. Vatan (2016)'a göre Beck'in (1964) "Bilişsel Terapisi” ve Ellis'in (1962) “Akılcı Duygulanım Davranışçı Terapisi”, Meichenbaum’un (1977) "BilişselDavranışsal Değişme Terapisi” ve Lazarus’un (1997) "Çok Boyutlu Terapisi” ikinci kuşak yaklaşımlara verilebilecek örnekler arasında yer almaktadır.

İlerleyen zamanla birlikte davranış ve biliş (düşünce) ikilisine duyguların katıldığı yaklaşımların gelişmeye başladığını görmekteyiz. Bu yaklaşımlar 'üçüncü kuşak' olarak anılmaktadır. Bunlar iç görü, farkındalık (mindfulness) ve kabul ile ilgili yaklaşımların baskın ve etkin olduğu uygulamalardır. Bu noktada birinci ve ikinci kuşakta, kişinin içsel yaşantılarının ihmal edildiği eleştirilmiştir. Bu eleştiriler kişinin içsel deneyimlerini çalışmakla ilgili yeni yöntemlerin ortaya konmasına zemin hazırlamıştır. Dolayısıyla, üçüncü kuşakta odak, içsel yaşantılara kaydırılmıştır. İçsel yaşantılar, davranışlar gibi üçüncü bir kişi tarafından açıkça gözlemlenip değerlendirilemeyeceği için, bu yaklaşımda, kişinin tüm bunları kendi farkındalı̆̆ı üzerinden ortaya koyması beklenmektedir. Üçüncü kuşak tedavi yaklaşımlarındaki ana temayı, söz konusu içsel deneyimlere dair farkındalık oluşturmaktadır. Bu kuşakta içsel deneyime dair farkındalık teşvik edilmekte ve farkındalığın devamında kabul sürecinin altı çizilmektedir. İçsel duyumları değiştirmek yerine 'kabul' vurgulanmaktadır (Herbert \& Forman, 2011).

Üçüncü kuşak, farkındalık ve kabul çalışmalarında temel odak noktası olarak duyguların açımlayıcı özellikleri üzerinde durmaktadır. Ayrıca üçüncü kuşakta psikopatolojilerin anlaşılmasında özellikle psikolojik belirtilerin ortaya çıkmasında ve sürdürülmesinde duygu düzenlemede yaşanan sıkıntılara sıklıkla vurgu yapılmaktadır. Bu özelliği sebebi ile üçüncü kuşak bilişsel davranışçı yaklaşımların alanyazında "Duygu Temelli Psikoterapi Yaklaşımları" olarak da adlandırıldığı görülmektedir.

Üçüncü kuşak olarak adlandırılabilen yaklaşımlar içerisinde; “dialektik davranış terapisi”" (DDT) (Linehan, 1993), "farkındalık temelli bilişsel terapi" (Segal, 2002), "kabul ve kararlılık terapisi” (Hayes \& Strosahl, 2004), "bütünleștirici duygu düzenleme terapisi”" (Mennin, 2010), "duygu düzenleme terapisi” (Berking, 2014) gibi örnekler yer almaktadır.

\section{2. Üçüncü Kuşak Olarak Adlandırılan Doğu Kökenli Yaklaşımlar}

Yukarıda belirtilen terapi yöntemlerinin dışında farkındalık temelli olarak adlandırılan doğu kökenli yaklaşımlardan uyarlanmış üçüncü kuşak yaklaşımlar da bulunmaktadır. Bu yaklaşımların genel olarak yoga, Budist 
meditasyonları, kadim Çin öğretilerinden Tao kökenli Qigong (Chi Kung) ve Tai Chi Chuan uygulamalarından temellendiği görülmektedir.

\section{GÜNCEL PSIKKOTERAPIDE DOĞU TEMELLİ YAKLAŞIMLARIN UYGULANMASI}

\subsection{Bilinçli Farkındalık Temelli Yaklaşımlar:}

Bilinçli farkındalık meditasyonları (mindfulness meditations, MMs) ve bilinçli farkındalık temelli yaklaşımlar (mindfulness-based interventions, MBIs) "farkındalık (mindfulness)" kavramı üzerine temellenmiş geniş yelpazede meditasyon ve psikolojik yaklaşımı içermektedir.

Kadim Budist meditasyonları olan Vipassana ve Zen meditasyonları, temel olarak 'bilinçli farkındalık meditasyonları' olarak (mindfulness meditations, MM) adlandırılırken; "farkındalık temelli stres azaltma programı" (mindfulness-based stres reduction, MBSR) (Kabat-Zinn, 1982), "farkındalık temelli bilişsel terapi" (mindfulness-based cognitive therapy, MBCT) (Segal vd., 2002), "dialektik davranış terapisi” (dialectical behavioral therapy, DBT) (Linehan, 1993) ve "kabul ve kararlılık terapisi" (acceptance and commitment therapy, ACT) (Hayes vd., 1999), alanyazında "bilinçli farkındalık temelli yaklaşımlar"(mindfulness-based interventions, MBI) olarak anılmaktadir.

Bu geleneksel meditatif uygulamalar "farkındalık" (mindfulness) adı altında batı psikolojisine ilk olarak, Jon Kabat-Zinn (1982) tarafından geliştirilen "farkındalık-temelli stres azaltma programı” (MBSR) ile tanıtılmıştır. Kabat-Zinn çalışmasında farkındalığı; kronik ağrı çeken hastalara semptomların ve kronik hastalıktan kaynaklanan stresin azaltılmasına yönelik bir beceri olarak öğretmiştir. Geliştirdiği programda geleneksel Budist meditasyonlarının özündeki farkındalık pratiğini ruhani kısmını eleyerek, bir anlamda sekülerleştirerek kullanmıştır (Kabat-Zinn, 2017). Günümüzde gelinen noktada birçok terapi yaklaşımının temelinde farkındalığı görmekteyiz.

Farkındalıkla ilgili alanyazında birçok operasyonel tanım bulunmaktadır. Farkındalık (mindfulness) kavramının İngilizce'deki isim babası olarak kabul edilen Kabat-Zinn'e (1994) göre "farkındalık”; dikkatin istemli bir şekilde ve yargısızca anlık deneyimlerin akışına yönlendirilmesidir. Dikkat sürekli olarak nefes alış-verişe, bedensel duyumlara, duygulara veya düşüncelerin akışına odaklanmaktadır. Farklı tanımlar gözden geçirildiğinde 'an'a yani, 'şimdi' ve 'burada'ya odaklı dikkat, içsel gözlem, yargısızlık, kabullenme ve serbest bırakmanın farkındalığın temel bileşenleri olduğunu söylemek mümkün görünmektedir.

Farkındalık temelli terapilerde amaç, çeşitli teknik ve alıştırmalarla danışanların farkındalık düzeyini arttırmaktır. Bir bölümü yoğun meditasyon uygulamaları içerirken, bir bölümü de bilişsel ve yaşantısal alıştırmalar kullanarak farkındalığı geliştirmeyi hedefler (Çatak \& Ögel, 2010).

Otuz yılı aşkın bir süredir batı psikolojisinde uygulanan farkındalık-temelli yaklaşımlara ilgi, her yıl artan bir hızda devam etmektedir. Görgül çalışmalarla günden güne uygulama alanları da genişlemektedir. Shonin (2014), 2003 yılında farkındalıkla ilgili yaklaşık 50 bilimsel makale yayınlanmışken, bu sayının 2013 yılında 600 civarında olduğunu belirtmektedir. Birleşik Krallık Ulusal Sağlık Kuruluşu (UK NIH) ve Amerikan Psikiyatri Birliği (APA) farkındalık temelli yaklaşımları, yetişkinlerde tekrarlayan depresyon rahatsızlığı için terapötik bir yaklaşım olarak resmi olarak tescillemiş bulunmaktadır. Bu yaklaşımlar ruh sağlığı alanında değil, eğitim, çalışma dünyası, tıp ve hatta askeri alanlarda da ilgi çekmiş ve uygulanmaya başlanmıştır (Shonin vd., 2014).

Bilimsel makalelerden elde edilen görgül bulgular; farkındalık temelli yaklaşımların birçok psikopatolojik rahatsızlık ve bozuklukların tedavisinde anlamlı sonuçlar ortaya koyduğunu göstermektedir. Örneğin; davranışsal bağımlılıklar kumar bağımlılığı, işkoliklik, travma sonrası stres bozukluğu, öfke bozuklukları, anksiyete bozuklukları, dikkat eksikliği hiperaktivite bozukluğu, fibromiyalji gibi ağrılı rahatsızlıklar, cinsel işlev bozuklukları, yeme bozuklukları, madde kullanımı, şizofreni-spektrumlu bozukluklar ve psikotik rahatsılıklar gibi (Shonin vd., 2014; Shonin vd., 2015).

MBSR ve MBCT meditasyon programlarında temel olarak üç farklı teknik kullanılmaktadır: beden taraması, oturma meditasyonu ve Hatha Yoga pratiği. 
"Farkındalık meditasyonu", zihni yargılama yapmaktan kaçınarak an be an eğitme işlevi görmektedir. Amaç, zihni maksimum düzeyde farkındalığa yönlendirmektir. Kişiler öncelikle duygu ve düşüncelerini dikkatle gözlemlemek için teşvik edilir, ardından düşüncelerinin içinde boğulmadan nasıl kalacakları ve düşüncelerinin geçip gitmesini yargılamaksızın nasıl izleyeceği öğretilmektedir. Yönergeler oldukça basittir. Temel nokta, kişinin dikkatini nefes alışverişine verebilmesini sağlamaktır. Dikkati başka bir noktaya kaydığg zaman, kişi bunu bilincinde olmal, düşüncelerin akıp gitmesine izin vermeli ve kendini zorlamadan dikkatini yeniden nefesine verebilmelidir (KabatZinn, 2009; Körükçü \& Kukulu, 2013).

"Beden taraması”, kişinin bedeni ile bağlantı kurmasına hizmet eden bir tekniktir. Kişi kendi bedeni üzerine kapsamlı ve anda kalarak odaklanmaktadır, böylece hem konsantrasyon hem de zihinsel esneklik geliştirebilmesi sağlanmış olmaktadır. Sırtüstü uzanılarak başlanan bu egzersizde ayak parmaklarından başlayarak başın tepesine kadar zihin, adım adım bedenin bir bölgesinden diğerine kaydırılır. Ve nefesin bedenin her bir noktasına etki ettiği hissedilir (Chiesa \& Malinowski, 2011; Körükçü \& Kukulu, 2013).

"Hatha yoga", farkındalık meditasyonu ile farkındalık temelli stres azaltma işlevi arasında bir bağlantı olarak kullanılmaktadır. Yoga pratiği; nefes egzersizlerinden, basit beden esnetme ve bedeni güçlendiren ve kasları rahatlatan beden duruşu düzenlemelerinden oluşmaktadır. Yoga duruşları oldukça yumuşaktır, bu nedenle farklı sağlık seviyelerindeki kişiler tarafından kolaylıkla uygulanabilmektedir. Egzersizler oturularak ya da ayakta yapılabilmektedir. Kişi egzersiz esnasında rahatsız edici düşüncelerle meşgul olmak yerine dikkatini yaptığ1 hareketlere verir, böylece zihin duruşa odaklanarak kişinin rahatlamasını zemin hazırlar. Yoga, ayrıca kişilerin esnekliklerinde fark edilir bir artışa ve bedenleri üzerinde daha fazla kontrol sahibi olmalarına yardımcı olur. Farkındalık temelli yoga egzersizleri istenilen yerde istenilen zamanlarda yapılabilmektedir (Chiesa \& Malinowski, 2011; Körükçü \& Kukulu, 2013).

Bu programlar genel olarak 8 haftalık bir programdan oluşmaktadır; haftada 1 gün 2 saatlik grup oturumu ve haftada 6 gün minimum 45 dakikalık ev ödevleri şeklinde düzenlenmektedir. Ancak yine de danışanların ihtiyaçlarına göre esneklik göstererek daha kısa ya da daha uzun kurslar da yapılabilmektedir, bu da bu programların güçlü yanlarından biridir (Kabat-Zinn, 1990; Shonin, 2015).

\subsection{Farkındalık Temelli Yaklaşımlarla İlgili Güncel Tartışma ve Eleștiriler: “Mcmindfulness” mı, Gelecek Vadeden Taze Bir Soluk mu?}

Kabat-Zinn'in "farkındalık (mindfulness)" kavramını batı psikolojisine kazandırmasından bu yana 30 yılı aşkın bir süredir farkındalık temelli psikoterapi yaklaşımları her yıl daha artan bir ilgiyle karşılanmakta ve bilimsel alan dışında da popüler kültürde hızlı bir ilgi yaratmaya devam etmektedir. Bu süreçte özellikle son on yıldır birtakım eleştiriler ve sorular da dillendirilmektedir.

(i) "Farkındalık temelli yaklaşımlar" geleneksel Budist kökenlerinden sekülerleştirilerek ayrıldığı ve hızlı bir şekilde batı psikoterapi dünyasına uyarlanmaya çalışıldığı için özündeki temel vasfı olan "doğru farkındalık (sammasati)" tan uzaklaşmakta olduğu, ruhani tarafı budandığı için saflığından ödün verildiği şeklinde bir eleştiri, uyarı yükselmektedir. Bu eleştirilerin dayandığı nokta, farkındalığın yalnızca 'an'da kalmaktan ibaret bir zihin durumu olmadığı, Budist geleneğin etik özüyle birlikte uygulanmadığında bu kaynaktan beslenemeyeceği, yine 2500 yıllık geçmişi olan Budist geleneğinde uyarıldığı gibi "yanlış farkındalık (micchasati)"'ye neden olacağı savıdır. Örneğin, farkındalığın askeri alanda kullanılıyor olması, Budist prensiplerden olan "ahimsa (şiddetsizlik)" ile çelişmektedir ve bu durumda "yanlış farkındalıktır". Bu eleştiriyi yapan hem alandaki deneyimli terapistler hem de kimi Budist öğretmenler bu yaklaşımların bu etikleri aktarabilmesi gerektiğini vurgulamaktadır (Purser \& Loy, 2013; Shonin vd., 2015, Van Gordon \& ark., 2016; Cohen, 2017).

(ii) Yine bu hızlı ve seküler yaklaşımın bir uzantısı olarak geleneksel Budist etiklerle bağı gevşetilen farkındalık temelli yaklaşımların etik olup olmadığı bir güncel tartışma konusudur. Her ne kadar KabatZinn ilk yıllardaki açıklamalarında sekülerleştirildiğini vurgulamışsa da son yıllardaki eleştirilere cevaben geliştirdiği programın Budist "Dharma" (Budizm öğretileri anlamına gelen Budist terim) geleneğinden çıktığını ve günümüz toplumlarına uyarlandığını belirtmektedir. Bu durumda gelen eleştiriler, eğer bu 
teknikler "Dharma"”yı baz alıyorsa insanlara bunun seküler olduğunun ifade edilmesinin etik olmadığ1 şeklindedir. Özetle, gerçekten seküler ise "Dharma" vurgusu ve öğretilerinin ayıklanması gerektiği, eğer "Dharma"'nın devamı kabul ediliyorsa da kişilere bunun açıkça ifade edilmesi gerektiği önerilmektedir (Shonin vd., 2015, Van Gordon vd., 2016).

(iii) En yoğun eleştirilerden bir tanesi de farkındalık temelli programların, çıkış bulduğu Budist öğretinin "aydınlama/uyanma" kavramına ters düşecek şekilde farkındalığın ticarileşmesine zemin hazırladığı, ticari bir meta haline getirildiği, insanların sistemden kaynaklanan acılarının, sorunlarının çözümünün toplumsal olarak bulunması yerine kişileri pasif kabul ediciliğe teşvik ettiği, statükonun devamına hizmet ettiği şeklindedir. Bu eleştiri "McMindfulness" ifadesi ile hicvedilmektedir (Purser \& Loy, 2013; Hyland, 2015; Shonin, 2015; Van Gordon vd., 2016; Cohen, 2017).

(iv) Bir diğer eleştiri konusu da hızlı ve artan ilgiyi karşılamak için yeterli pratik ve etik donanımı olan eğitmenlerin, uzmanların olmayışıdır. Yukarıda belirtilen eleştirileri dikkate alarak donanımlı ve etik yeterliliğe sahip uzmanların yetiştirilmesi için eğitim standartlarının hızlıca belirlenmesi gerekliliği vurgulanmaktadır (Shonin vd., 2015).

(v) Eleştirilerden bir tanesi de bazı çalışmaların metodolojisinin bilimsel yeterlilikleri karşılamadığı ile ilgili soru işaretleri olduğu yönünde (Shonin vd., 2015).

(vi) Bazı eleştiriler de meditasyonlu çalışmaların yan etkilerinin olabileceği, rapor edilmiş bazı vakalar olduğu şeklindedir; bunlar asosyallik, nihilistik eğilimler, meditasyona bağımlılık geliştirmek, bazı psikotik ataklar olarak sayılmaktadır. Ancak bu raporların genel toplam içinde çok düşük bir orana denk geldiği ve yoğun uygulamalarla tetiklenebildiği vurgulanmaktadır. Hem geleneksel hem de güncel meditatif yaklaşımlar doğru şekilde uygulandığında bu yan etkilerin görülmeyeceği hem araştırma bulguları hem de uzmanlar tarafından doğrulanmaktadır (Shonin vd., 2014; Shonin vd., 2015).

$\mathrm{Bu}$ eleştirilerin devamı olarak alanda yeni yapılanmaların ve düzenlemelerin yapıldı̆̆ını, güncel yaklaşımların oluştuğunu görmekteyiz.

Van Gordon ve ark. (2015), yukarıda bahsedilen sorunlara çözüm olarak güncel yaklaşımların geliştirildiğini belirtmektedirler ve bu yaklaşımları ayırabilmek için birinci "jenerasyon farkındalık temelli yaklaşımlar” (firstgeneration mindfulness based interventions, FG-MBIs) ve ikinci "jenerasyon farkındalık temelli yaklaşımlar” (second-generation mindfulness based interventions, SG-MBIs) tanımlamalarını yapmaktadırlar. SG-MBI yaklaşımları, FG-MBI yaklaşımlara göre daha "aktif ve seçici" bir farkındalık halini savunmaktadır. Bunun yanında SG-MBI yaklaşımlarda farkındalık eğitimi diğer meditatif pratiklerle beraber öğretilmektedir (örneğin, etik farkındalık, geçicilik, boşluk/egosuzluk, sevgi dolu nezaket ve şefkat meditasyonları). Yine artan ruhanilik de bu yaklaşımların içerdiği özellikler arasında görülmektedir.

Henüz ikinci jenerasyon yaklaşımlar çok yeni olduğu için iki grup arasındaki farkın gözlemlenebileceği yeterli bilimsel veri oluşturulamamıştır. Bu yönde bilimsel araştırmaların artması beklenmektedir.

\subsection{Geleneksel Çin Öğretilerinden Temellenen Yaklaşımlar:}

Bu grupta geleneksel Çin tıbbından ve Taoizm'den temellenen pratiklerin hem bedensel sağlık ve iyi olma hali hem de psikolojik iyi olma haline etkisi üzerine çalışmalar yapıldığını görmekteyiz. Ancak bu alan henüz yukarıda detaylandırılan "farkındalık temelli yaklaşımlar" kadar araştırılan bir alan olmasa da yıldan yıla daha fazla ilgi çekmektedir. Abbott ve Lavretsky (2013); 2002 yılında ABD'de Tai Chi uygulayanların sayısı 2.5 milyonu aşarken, Qigong için bunun 500 binin üzerinde olduğunu raporlamaktadır. Yapılan bilimsel çalışmalar olumlu sonuçlar vermekle birlikte, daha fazla araştırmanın yapılması gerekliliği bilimsel makalelerde özellikle vurgulanmaktadır.

Çin kaynakları, Qigong'un 5 bin yıllık bir geçmişe sahip olduğunu belirtmektedir. Geleneksel Çin tıbbının kollarından biri olan Qigong kısaca beden-zihin tıbbı olarak adlandırılmaktadır. Genel olarak içsel ve dışsal Qigong olarak ikiye ayrılmaktadır. İçsel Qigong; nefes ve meditasyon ile uyumlu bir şekilde yapılan yumuşak bedensel egzersiz ve rahatlama uygulamalardan oluşmaktadır. Bu uygulamaların bedende dengeyi desteklediği ve bedende yaşam enerjisinin doğal olarak akmasını sağladığı için enerji blokajlarını çözdüğüne inanılmaktadır. Dışsal Qigong ise Qigong uygulayıcısının hastayı tedavi etmek için Qi (Chi/enerji formu) göndermesini veya çekmesini içeren diğer bir 
enerji tıbb1 dalıdır (Chan vd., 2010; Oh vd., 2013; Abbott \& Lavretsky, 2013; Wang vd., 2013, Wang vd., 2014; Chang vd., 2018; Guo vd., 2018). Ancak bu derlemenin konusu dışsal Qigong uygulamaları değildir.

Geleneksel Çin tıbbında pek çok faklı ekol ve uygulama seti bulunmaktadır. Bunlardan güncel uygulamalarda daha çok kullanılanlar Tai Chi Chuan ve sağlık Qigongu setleridir. Örneğin, "Ağaç Duruşu", "Baduanjin”, "Beş Hayvan Oyunu", "Shaolin Dan Tian Nefesi" gibi uygulama setlerinin kullanıldığını görmekteyiz (Chan vd., 2011; Oh vd., 2013; Abbott \& Lavretsky, 2013; Wang vd., 2013, Wang vd., 2014; Chang vd., 2018; Guo vd., 2018).

Yapılan bilimsel çalışmalar Qigong uygulamalarının tansiyon, beden koordinasyonu, kas gücü ve uyku kalitesini olumlu yönde etkilediği gibi, zihinsel faaliyetleri de desteklediği; ankisiyete bozuklukları, majör depresyon, travma sonrası stres bozuklukları, tükenmişlik sendromu ve stresle baş etme durumlarında da olumlu sonuçlar ortaya koyduğu gözlemlenmiştir. Ayrıca, EEG (elektroensefalografi) ölçümleri ile Qigong uygulamalarının beyinde alfa ve theta frekanslarını yükselttiği, beta frekansını düşürdüğü bulgularına ulaşan bilimsel araştırmalar da bulunmaktadır. Alfa ve theta frekansları; rahatlama ve uyanık/farkındalığı yüksek zihin durumu ile ilişkilendirilmektedir (Chan vd., 2010; Oh vd., 2013; Abbott \& Lavretsky, 2013; Wang vd., 2013, Wang vd., 2014; Chang vd., 2018; Guo vd., 2018). Özellikle anksiyete, stres, depresyon ve düşük alfa-theta frekansları ile ilişkilendirilen psikopatolojik bozukluklar için bu çalışmalar gelecek vadediyor gibi görünmektedir. Yine de bu çalışmaların daha da arttırılması gerekliliği göz önünde bulundurulmalıdır.

\subsection{Türkiye'deki Çalışmalar}

Türkiye'de farkındalık temelli yaklaşımların uygulanmasının dünya geneline göre oldukça geriden geldiğini görmekteyiz. Derleme makaleler ile ülkemizdeki psikoloji camiasına tanıtılması 2010 kadar yakın bir tarihe denk gelmektedir. Sonrasında hem akademik çalışmalarda hem de operasyonel çerçevede terapilerde uygulamalara başlandığı görülmektedir. Bu süreçte, '18 farkındalık ölçeği' yüksek düzeyde geçerlilik ve güvenilirlik sonuçları ile Türkçe'ye uyarlanmıştır (Özyeşil vd, 2011; Çatak, 2012; Kınay, 2013; Şahin \& Yeniçeri, 2015; Atalay vd., 2017; Kırca, 2107; Çelik \& Onat-Kocabıyık, 2018; Aslan Gördesli vd., 2018; Erus \& Deniz, 2018; Sarıçam \& Çelik, 2018; Aslan-Gördesli vd., 2019; Ayalp \& Hisli Şahin, 2018; Erus \& Tekel, 2020; Turan, 2020; Tingaz, 2020):

- Özyeşil ve ark. (2011) tarafından Bilinçli Farkındalık Ölçeği (Mindful Attention Awareness Scale-MAAS, Brown ve Ryan, 2003)

- Çatak (2012) tarafından Bilinçli Farkındalık Ölçeği (Mindful Attention Awareness Scale-MAAS, Brown ve Ryan, 2003)

- Çatak (2012) tarafından Bilişsel ve Duygusal Bilinçli Farkındalık Ölçeği-Revizyon (Cognitive and Affective Mindfulness Scale-Revised (CAMS-R), Feldman ve ark., 2007)

- Kınay (2013) tarafından Beş Boyutlu Bilinçli Farkındalık Ölçeği (Five-Facet Mindfulness Questionnaire, Baer ve ark., 2004)

- Şahin ve Yeniçeri (2015) tarafindan Psikolojik Farkındalık Ölçeği (Psychological Mindedness Scale; Conteve ark. 1996),

- Şahin ve Yeniçeri (2015) tarafından Bütünleştirici Kendilik Farkındalı̆̆ Ölçeği (Integrative Self-Knowledge Scale (Ghorbani ve ark., 2008))

- Şahin ve Yeniçeri (2015) tarafından Toronto Bilgece Farkındalık Ölçeği (Toronto Mindfulness Scale-(Trait, Lau ve ark., 2006))

- Atalay ve ark. (2017) tarafından Bilinçli Farkındalık Temelli Öz-yeterlik Ölçeği-Yenilenmiş (MindfulnessBased Self Efficacy Scale-Revised (Cayoun vd., 2012))

- Kırca (2017) tarafından Ergenler İçin Kapsamlı Bilinçli Farkındalık Deneyimleri Envanteri (The Comprehensive Inventory of Mindfulness Experiences-Adolescents (CHIME-A) (Johnson vd., 2017))

- Çelik ve Onat-Kocabıyı (2018) tarafından Philadelphia Farkındalık Ölçeği (PFÖ) (The Philadelphia Mindfulness Scale-PHLMS (Cardaciotto vd., 2008))

- Aslan Gördesli ve ark. (2018) tarafından Ebeveynlikte Bilinçli Farkındalık Ölçeği (The Mindfulness In Parenting Questionnaire (McCaffrey vd., 2017)) 
- Erus ve Deniz (2018) tarafından Evlilikte Bilinçli Farkındalık Ölçeği

- Sarıçam ve Çelik (2018) tarafından Ergen ve Yetişkin Bilinçli Farkındalık Ölçeği (EYBFÖ) (Adolescentand Adult Mindfulness Scale (AAMS) (Droutman vd., 2018))

- Aslan-Gördesli ve ark. (2019) tarafından Öğretimde Bilinçli Farkındalık Ölçeği (The Mindfulness in Teaching Scale (MTS) (Frank vd., 2016))

- Ayalp ve Hisli Şahin (2018) tarafından Beş Faktörlü Bilgece Farkındalık Ölçeği-Kısa Formu (BFBFÖ-K) (Five Facet Mindfulness Questionnaire - Short Form (FFMQ-S) (Tran vd., 2013))

- Erus ve Tekel (2020) tarafından Kişilerarası Farkındalık Ölçeği

- Turan (2020) tarafından Bilinçli Farkındalık Ölçeği Ergen Formu (Mindful Attention Awareness ScaleAdolescent Form (MAAS-A) (Brown vd., 2011))

- Tingaz (2020) tarafından Sporcu Bilinçli Farkındalık Ölçeği (Mindfulness Inventory for Sport (Thienot vd., 2014))

Qigong uygulamaları ile ilgili olarak alanda henüz tek bir çalışma olduğunu görmekteyiz (Denizli, 2015).

\section{SONUÇ VE ÖNERİLER}

Psikoterapi alanında 30 yılı aşkın bir süredir köklerini geleneksel Doğu yaklaşımlarından alan farkındalık ve meditasyon temelli yaklaşımlar artarak uygulanmakta ve ilgi görmektedir, günlük yaşamda da insanlar arasında hızla popülerlik kazanmaktadır. Bilimsel araştırma bulguları oldukça olumlu veriler sunsa da alandaki uzmanlar ve terapistler hem operasyonel tanımlar hem de standart eğitim modelleri geliştirilebilmesi için daha fazla çalışmaya ihtiyaç duyulduğunu belirtmektedirler. Bugüne kadar genel olarak Batı ekollerinin etkisi altında gelişen psikoloji alanında Doğu uygulamalarının uyarlanarak kullanılacağı yeni modelleri daha yaygın göreceğimizi söylemek mümkün. Batı psikolojinde görmeye alışık olduğumuz üzere terapist-danışan/hasta ekseninde dışarıdan içeriye müdahale ile şekillenen psikolojik iyi olma halinin, belki de terapist müdahalesine bile gerek kalmadan danışanın farkındalığının arttırılması ile içeriden dışarıya doğru bir yönelimle düzenleneceği bir gelecek bizi beklemekte olabilir.

Ülkemizde de farkındalık temelli yaklaşımların ve Qigong gibi beden-zihin uygulamalarının terapi süreçlerine uyarlanması ile ilgili araştırmaların ve çalışmaların artması beklenmektedir. Bu yaklaşımların terapi süreçlerine katkısının nasıl olabileceğinin bilimsel zeminde incelenmesi daha bütüncül yaklaşımlar arayan terapistler için de yeni bir alan açacaktır.

Önerilerden bazıları şöyle sıralanabilir;

- Kontrol gruplu deneysel uygulama çalışmalarının sayısının arttırılmasında fayda vardır. Bu yaklaşımların etkililik alanları ve yetersiz kaldıkları alanlar netleştirilerek güncel psikoterapi yaklaşımları ile nasıl ilişkilendirilebileceğine dair yol haritasına katkı sağlanabilir.

- Deneysel araştırmalar; programın uygulama süresi konusunda çeşitlendirilebilir, böylece danışanlar için en optimum uygulama süreleri belirlenebilir (mesela 4, 6, 8, 10, 12 haftalık ya da uzun programlar vs. gibi).

- Farklı danışan gruplarına uygulanabilecek farklı uygulama setlerini içeren deneysel araştırmalar çeşitlendirilebilir.

- Yine birim uygulama süresinin uzunluğu ile deneysel çalışmalar arttırılabilir (mesela 20, 30, 40, 50, $60 \mathrm{dk}$. veya daha uzun süreler gibi).

- Demografik farklılıklarla ilgili programlarda düzenleme ihtiyacı var mıdır, deneysel çalışmalarda cevap aranabilecek noktalardan biri de bu olabilir (örneğin yaş grupları, cinsiyet ya da eğitim durumu gibi).

\section{ETİK BEYANI}

Yapılan araştırma için etik kurul iznine gerek yoktur.

\section{YAZAR KATKILARI}

Araştırmanın tüm bölümleri EA tarafından yapılmıştır. 


\section{KAYNAKLAR}

Abbott, R., \& Lavretsky, H. (2013). Tai chi and qigong for the treatment and prevention of mental disorders. The Psychiatric Clinics of North America, 36(1), 109. https://doi.org/10.1016/j.psc.2013.01.011

Acevedo, B. P., Pospos, S., \& Lavretsky, H. (2016). The neural mechanisms of meditative practices: Novel approaches for healthy aging. Current Behavioral Neuroscience Reports, 3(4), 328-339. https://doi.org/10.1007/s40473-016-0098-x

Aslan Gördesli, M., Arslan, R., Çekici, F., Aydın Sünbül, Z., \& Malkoç, A. (2018). The psychometric properties of the mindfulness in parenting questionnaire in turkish sample. European Journal of Education Studies, 5(5), 175-188. https://doi.org/10.5281/zenodo.1477467

Aslan-Gördesli, M., Arslan, R., Çekici, F., Aydın-Sünbül, Z., \& Malkoç, A. (2019). The psychometric properties of the mindfulness in teaching scale in a turkish sample. Universal Journal of Educational Research, 7(2), 381-386. https://doi.org/10.13189/ujer.2019.070210

Ayalp, H. D. \& Hisli Şahin, N. (2018). Beş faktörlü bilgece farkındalık ölçeği-kısa formu'nun (BFBFÖ-K) Türkçe uyarlamas1. Klinik Psikoloji Dergisi, 2(3), 117-127. https://doi.org/10.31828/kpd2602443807092018m000002

Baer, R. A. (2003). Mindfulness training as a clinical intervention: A conceptual and empirical review. Clinical psychology: Science and practice, 10(2), 125-143.

Baer, R. A. (2007). Mindfulness, assessment, and transdiagnostic processes. Psychological Inquiry, 18(4), $238-271$. https://doi.org/10.1080/10478400701598306

Chan, A. S., Cheung, M. C., Sze, S. L., Leung, W. W. M., \& Shi, D. (2010). Shaolin dan tian breathing fosters relaxed and attentive mind: A randomized controlled neuro-electrophysiological study. Evidence-Based Complementary and Alternative Medicine, 2011. https://doi.org/10.1155/2011/180704

Chang, P. S., Knobf, M. T., Oh, B., \& Funk, M. (2018). Physical and psychologica leffects of qigong exercise in communitydwelling older adults: An exploratory study. Geriatric Nursing, 39(1), 88-94. https://doi.org/10.1016/j.gerinurse.2017.07.004

Chiesa, A., \& Malinowski, P. (2011). Mindfulness-based approaches: Are they all the same?. Journal of Clinical Psychology, 67(4), 404-424. https://doi.org/10.1002/jclp.20776

Cohen, E. (2017). Cutting the Buddha's body to fit the neoliberal suit: Mindfulness-from practice, to purchase, to praxis. Annual Review of Critical Psychology, 13. https://eprints.leedsbeckett.ac.uk/id/eprint/3914/

Çatak, P.D., Ögel, K. (2010). Farkındalık temelli terapiler ve terapötik süreçler. Klinik Psikiyatri Dergisi, 13(2), 85-91. https://jag.journalagent.com/kpd/pdfs/KPD_13_2_85_91.pdf

Çatak, P. D., \& Ögel, K. (2010). Bir terapi yöntemi olarak farkındalık. Noro-Psikyatri Arsivi, 47(1), 69-73.

Çatak, P. D. (2012). The Turkish version of mindful attention awareness scale: Preliminary findings. Mindfulness, 3(1), 1-9. https://doi.org/10.1007/s12671-011-0072-3

Çatak, P. D. (2012). The Turkish version of the cognitive and affective mindfulness scale-revised. Europe's Journal of Psychology, 8(4), 603-619. https://doi.org/10.5964/ejop.v8i4.436

Çelik, H. \& Onat-Kocabıyık, O. (2018). Philadelphia Farkındalık Ölçeği (PFÖ)'nin Türkçe formunun psikometrik özellikleri. Uluslararası Eğitim Araştırmaları, 48(48), 128-144. https://doi.org/10.15285/maruaebd.345925

Demir, V. (2017). Bilinçli farkındalık temelli bilişsel terapi programının üniversite öğrencilerinin kaygı düzeylerine etkisi. OPUS Uluslararası Toplum Araştırmaları Dergisi, 7(12), 98-117. https://doi.org/10.26466/opus.294058

Demir, V. (2015). Bilinçli farkındalık temelli kognitif terapi programının bireylerin depresif belirti düzeyleri üzerine etkisi. Psikoloji Çalışmaları Dergisi, 35(1), 15-26. https://dergipark.org.tr/en/pub/iupcd/issue/9442/118113

Denizli, U. (2015). Çalışma hayatında Tai Chi: Bir alan deneyi örneği. Global Journal of Economics and Business Studies, 4(8), 88-96. https://dergipark.org.tr/en/pub/gumusgjebs/issue/24946/263331

Erus, S. M. \& Deniz, M. E. (2018). Evlilikte bilinçli farkındalık ölçeğinin geliştirmesi: Geçerlik ve güvenirlik çalışması. The $\begin{array}{lllll}\text { Journal of Happiness } \quad \text { Well-Being, } & 6(2), & 96-113\end{array}$ http://psikiyatridizini.net/viewarticle.aspx?articleid=40207\&tammetinvar=yes

Erus, S. M., \& Tekel, E. (2020). Development of interpersonal mindfulness scale-tr (IMS-TR): Validity and reliability. European Journal of Educational Research, 9(1), 103-115. https://doi.org/10.12973/eu-jer.9.1.103

Evans, S., Ferrando, S., Findler, M., Stowell, C., Smart, C, \& Haglin D (2008). Mindfulness-based cognitive therapy for generalized anxiety disorder. Journal of Anxiety Disorders, 22(4), 716-721. https://doi.org/10.1016/j.janxdis.2007.07.005

Grepmair, L., Mitterlehner, F., Loew, T., Bacher, E., Rother, W., \& Nickel, M. (2007). Promoting mindfulness in psychotherapists in training influences the treatment results of their patients: A randomized, double-blind, cotrolled study. Psychter Psychosom, 76(6), 332-338. https://doi.org/10.1159/000107560 
Guo, Y.,Xu, M., Zhang, J., Hu, Q., Zhou, Z., Wei, Z., \& Wang, Y. (2018). The effect of three-circle post standing (zhanzhuang) qigong on the physical and psychological well-being of college students: Study protocol for a randomized controlled trial. Medicine, 97(38). https://doi.org/10.1097\%2FMD.0000000000012323

Gülüm, İ. V. (2016). Etkili terapist özellikleri için farkındalık eğitim ve uygulamaları: Bir meta-sentez çalışması. Psikiyatride Güncel Yaklaşımlar, 8(4), 337-353. https://doi.org/10.18863/pgy.253439

Henz, D., \& Schöllhorn, W. I. (2018). Temporal courses in EEG theta and alpha activity in the dynamic health qigong techniques wu qin xi and liu zi jue. Frontiers in Psychology, 8, 2291. https://doi.org/10.3389/fpsyg.2017.02291

Kabat-Zinn, J. (1994). Wherever you go, there you are: Mindfulness meditation in everyday life. Hyperion.

Kabat-Zinn, J. (2003). Mindfulness-basedinterventions in context: Past, present, andfuture. Clinical Psychology: Science and Practice, 10(2), 144-156. https://doi.org/10.1093/clipsy.bpg016

Kabat-Zinn, J., \& Shonin, E. (2016). This is not momindfulness by any stretch of the imagination. The Psychologist, the Monthly Publication of The British Psychological Society, 29(2). https://thepsychologist.bps.org.uk/not-mcmindfulness-any$\underline{\text { stretch-imagination }}$

Kırca, B. (2017). Ergenler için kapsamlı bilinçli farkındalık deneyimleri envanterinin geçerlik ve güvenirlik çalışması [Yayınlanmamış Yüksek Lisans tezi]. İstanbul Sabahattin Zaim Üniversitesi.

Kimbrough, E., Magyari, T., Langenberg, P., Chesney, M., \& Berman, B. (2010). Mindfulness intervention for child abuse survivors. Journal of Clinical Psychology, 66(1), 17-33. https://doi.org/10.1002/jclp.20624

Körükçü, Ö., \& Kukulu, K. (2015) Beden-zihin-ruh bütünlüğünü korumaya yönelik bir program: Farkındalık temelli stres azaltma program1. Psikiyatride Güncel Yaklaşımlar, 7(1), 68-80. https://doi.org/10.5455/cap.20140504031811

Kristeller, J., Wolever, R. Q., \& Sheets, V. (2014). Mindfulness-based eating awareness training (MB-EAT) for binge eating: A randomized clinical trial. Mindfulness, 5(3), 282-297. https://doi.org/10.1007/s12671-012-0179-1

Oh, B., Choi, S. M., Inamori, A., Rosenthal, D., \& Yeung, A. (2013). Effects of qigong on depression: A systemic review. Evidence-Based Complementary and Alternative Medicine, 2013. https://doi.org/10.1155/2013/134737

Ögel K., Sarp N., Gürol D.T., \& Ermağan E. (2014). Bağımlı olan ve olmayan bireylerde farkındalık (mindfulness) ve farkındalığı etkileyen etkenlerin incelenmesi. Anadolu Psikiyatri Dergisi, $15, \quad 282-288$. https://eds.p.ebscohost.com/eds/pdfviewer/pdfviewer?vid=0\&sid=3c8e30d3-f3bd-4f38-bef0-e156075982e7\%40redis

Özyeşil, Z., Arslan, C., Kesici, Ş., \& Deniz, M. E. (2011). Bilinçli farkındalık ölçeği’ni Türkçeye uyarlama çalışması. Eğitim ve Bilim, 36(160), 224-235. http://eb.ted.org.tr/index.php/EB/article/view/697/271

Purser, R., \& Loy, D. (2013). Beyond mcmindfulness. Huffington Post, 1(7), 13. https://tanyaforgan.com/wpcontent/uploads/sites/5/2014/04/McMindfulnesBeyonds.pdf

Shapiro, S. L. (2009). The integration of mindfulness and psychology. Journal of Clinical Psychology, 65(6), 555-560. https://doi.org/10.1002/jclp.20602

Sargın, A.E., \& Sargın, M. (2015). Bir gözden geçirme: Sınırda kişilik bozukluğu ve diyalektik davranışçı terapi. Türkiye Klinikleri J Psychiatry Topics, 8(4). https://www.turkiyeklinikleri.com/article/en-bir-gozden-gecirme-sinirda-kisilikbozuklugu-ve-diyalektik-davranisci-terapi-73138.html

Sarıçam, H., \& Çelik, İ. (2018). Ergen ve Yetişkin Bilinçli Farkındalık Ölçeği (EYBFÖ) Türkçe formunun psikometrik özellikleri. VIII. Uluslararası Eğitimde Araştırmalar Kongresi - ICRE 2018 Özet Kitabı (ID:18390).

Shonin, E., Van Gordon, W., \& Griffiths, M. D. (2014). Are there risks associated with using mindfulness for the treatment of psychopathology?. Clinical Practice, 11(4), 389-392. http://irep.ntu.ac.uk/id/eprint/25868/1/221391_2996.pdf

Shonin, E. S., Van Gordon, W., \& Griffiths, M. D. (2015). Mindfulness in psychology: a breath of fresh air?. The Psychologist, 28(1), 28-31. http://irep.ntu.ac.uk/id/eprint/25968/1/221445_2981.pdf

Şahin, N. H., \& Yeniçeri, Z. (2015). “Farkındalık” üzerine üç araç: Psikolojik Farkındalık, Bütünleyici Kendilik Farkındalı̆̆g ve Toronto Bilgece Farkındalı ölçekleri. Türk Psikoloji Dergisi, 30(76), 48-64. http://www.psikolog.org.tr/tr/yayinlar/dergiler/1031828/tpd1300443320150000m000036.pdf

Tingaz, E. O. (2020). Sporcu Bilinçli Farkındalık (mindfulness) Ölçeği: Türkçeye uyarlama, geçerlik ve güvenirlik çalışması. Spormetre: Beden Eğitimi ve Spor Bilimleri Dergisi, 18(1), 71-80. https://doi.org/10.33689/spormetre.642682

Turan, M. E. (2020). Bilinçli Farkındalık Ölçeği Ergen Formu'nun geçerlik ve güvenirlik çalışması. OPUS International Journal of Society Researches, 5608-5625. https://doi.org/10.26466/opus.683364

Van Gordon, W., Shonin, E., \& Griffiths, M. D. (2015). Towards a second generation of mindfulness-based interventions. Australian \& New Zealand Journal of Psychiatry, 49(7), 591-592. https://doi.org/10.1177/0004867415577437

Van Gordon, W., Shonin, E., \& Griffiths, M. D. (2016). Are contemporary mindfulness-based interventions unethical?. British Journal of General Practice, 66(643), 94-94. https://doi.org/10.3399/bjgp16X683677

Vatan, S. (2016). Bilişsel davranışçı terapilerde üçüncü kuşak yaklaşımlar. Psikiyatride Güncel Yaklaşımlar, 8(3), $190-203$. https://doi.org/10.18863/pgy.238183 
Vøllestad, J., Sivertsen, B., \& Nielsen, G. H. (2011). Mindfulness-based stress reduction for patients with anxiety disorders: Evaluation in a randomized controlled trial. Behaviour Research And Therapy, 49(4), 281-288. https://doi.org/10.1016/j.brat.2011.01.007

Wang, C. W., Chan, C. L. W., Ho, R. T., Tsang, H. W., Chan, C. H. Y., \& Ng, S. M. (2013). The effect of qigong on depressive and anxiety symptoms: a systematic review and meta-analysis of randomized controlled trials. Evidence-Based Complementary and Alternative Medicine, 2013. https://doi.org/10.1155/2013/716094

Wang, C. W., Chan, C. H., Ho, R. T., Chan, J. S., Ng, S. M., \& Chan, C. L. (2014). Managing stress and anxiety through qigong exercise in healthy adults: a systematic review and meta-analysis of randomized controlled trials. BMC Complementary and Alternative Medicine, 14(1), 1-9. https://doi.org/10.1186/1472-6882-14-8 